\title{
A CREMATED BONE INTERCOMPARISON STUDY
}

\author{
Philip Naysmith ${ }^{1,2} \bullet$ E Marian Scott ${ }^{3} \bullet$ Gordon T Cook $^{1} \bullet$ Jan Heinemeier ${ }^{4} \bullet$ \\ Johannes van der Plicht ${ }^{5} \cdot$ Mark Van Strydonck ${ }^{6} \bullet$ Christopher Bronk Ramsey $^{7} \bullet$ \\ Pieter M Grootes ${ }^{8} \bullet$ Stewart P H T Freeman $^{1}$
}

\begin{abstract}
It is now almost $10 \mathrm{yr}$ since radiocarbon dating of cremated bone was first developed using the small carbonate component contained within the hydroxyapatite-based inorganic fraction. Currently, a significant number of ${ }^{14} \mathrm{C}$ laboratories date cremated bone as part of their routine dating service. As a general investigation of cremated bone dating since this initial development, a small, cremated bone intercomparison study took place in 2005, involving 6 laboratories. Six cremated bone samples (including 2 sets of duplicates), with ages spanning approximately 1500-2800 BP, were sent to the laboratories. The results, which showed relatively good agreement amongst the laboratories and between the duplicate samples, are discussed in detail.
\end{abstract}

\section{INTRODUCTION}

For over $50 \mathrm{yr}$, archaeologists have used radiocarbon dating to reconstruct the past. Typical archaeological samples dated routinely include charcoal, wood, human bone, and shell, and increasingly this is carried out using accelerator mass spectrometry (AMS). AMS has provided an opportunity to date other sample types with low carbon content such as cremated bone. Lanting and Brindley (1998) were the first to propose that it might be possible to date cremated bone using the small structural carbonate component $(0.5-1 \%)$ contained within the hydroxyapatite (or bio-apatite). However, despite a significant number of paired analyses of cremated bone and associated samples (mainly charcoal) (Lanting and Brindley 1998; Lanting et al. 2001; De Mulder et al. 2004), there still remains some debate over the reliability of cremated bone as ${ }^{14} \mathrm{C}$-datable material.

As part of an ongoing interlaboratory comparison program, the Fifth International Radiocarbon Intercomparison (VIRI), a large-scale bone intercomparison was undertaken. It was not possible to include cremated bone in the wider intercomparison since sample sizes limited the number of laboratories that could participate. However, carrying out a small-scale intercomparison of cremated bone provides a valuable opportunity to assess the reproducibility of the method and hence contribute to its validation. Thus, 6 cremated bone samples, including 2 pairs of duplicate samples, were sent to a small group of laboratories that routinely date this material. Duplicate samples were considered important as they allow an assessment of the intralaboratory variability. The objectives of the cremated bone intercomparison were to assess:

- The agreement between duplicates;

- The overall agreement amongst the laboratories and hence the reproducibility of the method.

\footnotetext{
${ }^{1}$ Scottish Universities Environmental Research Centre, Rankine Avenue, Scottish Enterprise Technology Park, East Kilbride, G75 0QF, United Kingdom.

${ }^{2}$ Corresponding author. Email: P.Naysmith@suerc.gla.ac.uk.

${ }^{3}$ Department of Statistics, University of Glasgow, United Kingdom.

${ }^{4}$ University of Aarhus, Denmark.

${ }^{5}$ University of Groningen and Leiden University, the Netherlands.

${ }^{6}$ Royal Institute for Cultural Heritage, Belgium.

${ }^{7}$ Oxford Radiocarbon Accelerator Unit, Oxford, United Kingdom.

${ }^{8}$ Leibniz Laboratory, Christian Albrechts University, Germany.
} 
Six laboratories agreed to take part in the study and these are listed in Table 1. Five of the laboratories that took part are AMS laboratories and one prepares targets to be measured at one of the participating AMS laboratories.

Table 1 Participating laboratories.

\begin{tabular}{ll}
\hline Laboratories & Lab code \\
\hline AMS ${ }^{14}$ C Dating Centre, Aarhus, Denmark & AAR \\
Leibniz Labor, Kiel, Germany & KIA \\
Groningen ${ }^{14}$ C laboratory, Groningen, the Netherlands & GrA \\
Royal Institute for Cultural Heritage (KIK), Brussels, Belgium & IRPA \\
SUERC ${ }^{14}$ C Laboratory, East Kilbride, Scotland & SUERC \\
Research Lab for Archaeology, Oxford, England & OxA \\
\hline
\end{tabular}

\section{Cremated Bone}

The standard pretreatment method for bone samples derived from inhumations (i.e. unburnt bone) is to extract and purify the collagen component. Collagen is a protein that forms long fibers, which give bone its slight give and therefore its strength (Mays 1998). In living material, collagen comprises about $20-30 \%$ by weight of dry bone. The other $70 \%$ is a crystalline form of calcium phosphate termed hydroxyapatite (or bio-apatite), which is embedded in the collagen (Mays 1998). This hydroxyapatite incorporates about $0.5-1 \%$ by weight of carbonate as a substitute for phosphate (Lanting and Brindley 1998). A cremated bone contains no collagen. It is a bone sample that has been heated to temperatures above $600{ }^{\circ} \mathrm{C}$ in a cremation pyre. It should also contain no charred organic material and should be gray/white in color. During the cremation, the hydroxyapatite recrystallizes and compacts, resulting in a structure that is resistant to subsequent carbonate exchange (Van Strydonck et al. 2005).

\section{Cremated Bone Dating}

Most of the laboratories that regularly date cremated bone use the method described in Lanting et al. (2001). Briefly, the bone apatite is purified using $1.5 \%$ sodium hypochlorite to remove organic material and $1 \mathrm{M}$ acetic acid to remove the readily soluble carbonate ions. The apatite yield is about $85 \%$, and the $\mathrm{CO}_{2}$ is released by its reaction with oversaturated phosphoric acid. This is followed by $\mathrm{CO}_{2}$ purification and conversion to graphite, followed by AMS measurement. Some laboratories have noted that the $\mathrm{CO}_{2}$ liberated by phosphoric acid could not always be graphitized due to sulphur contamination and use combustion with copper oxide and silver to clean the $\mathrm{CO}_{2}$ prior to graphitization.

A modification of the method adopted by the KIK laboratory is to treat the bone material with $15 \mathrm{~mL} 1 \% \mathrm{HCl}$ and then titrate with concentrated $\mathrm{HCl}$ so that about $50 \%$ of the material is leached away, removing the secondary calcite concentrated on the outside of the sample. The $\mathrm{CO}_{2}$ is then liberated from the remaining sample using $100 \%$ phosphoric acid at $90^{\circ} \mathrm{C}$ and then combusted with $\mathrm{CuO}$ and silver wool at $900{ }^{\circ} \mathrm{C}$ for $4 \mathrm{hr}$ to remove the sulphur (and other contaminants).

\section{The Intercomparison Study}

The cremated bone samples used in the intercomparison were from sites in Holland and Belgium and were provided by Hans van der Plicht and Mark Van Strydonck from samples that had been previously dated or had associated grave material; thus, although the samples were not of known age, their approximate age by association was known. The Wapse dates are based on associated charcoal 
dates from Groningen (GrN-10438, $2780 \pm 40$ and $\mathrm{GrN}-7418,2805 \pm 35)$. Six samples were sent out to each laboratory. Table 2 illustrates the samples that were sent out with their descriptions and expected ages.

Table 2 The cremated bone samples and associated information.

\begin{tabular}{lll}
\hline Sample nr & Sample description & Expected age \\
\hline 1 & Wapse 1 excavated 1955 X1.3 & $2780 \pm 40$ BP \\
2 & Brochem 1 excavated 2001-2003 Trace 390 & 6th-7th century AD \\
3 & Wapse 2 excavated 1955 X1.65 & 2805 \pm 35 BP \\
4 & Brochem 2 excavated 2001-2003 Trace 447 & 6th-7th century AD \\
5 & Brochem 1 excavated 2001-2003 Trace 390 & 6th-7th century AD \\
6 & Wapse 1 excavated 1955 X1.3 & 2780 \pm 40 BP \\
\hline
\end{tabular}

Within the 6 samples, there were 2 sets of duplicates, namely samples 1 and 6 and samples 2 and 5 . Three to $4 \mathrm{~g}$ of dry bone were sent to each laboratory with a deadline for results of the end of 2005 .

\section{RESULTS}

A total of 64 analyses were reported and these are shown in Table 3, with the summary statistics given in Table 4 . All the replicate results are reported to allow an assessment of the within laboratory variability. Figure 1 shows the scatter of results for the individual samples.

Table $3{ }^{14} \mathrm{C}$ results for cremated bone analyses.

\begin{tabular}{lllllll}
\hline Sample nr & Aarhus & SUERC & KIK & Oxford & Groningen & Kiel $^{\text {a }}$ \\
\hline 1 & No result & $2820(40)$ & $2735(25)$ & $2789(34)$ & $2795(35)$ & $2775(25)$ \\
& & $2760(35)$ & & $2873(29)$ & & \\
& & & & $2764(29)$ & & \\
& $1529(38)$ & $1455(40)$ & $1520(30)$ & $1537(29)$ & $1565(35)$ & $1450(25)-\mathrm{A}$ \\
& $1455(38)$ & $1425(35)$ & & $1571(24)$ & & $1515(30)-\mathrm{B}$ \\
3 & & & & & & $1430(35)-\mathrm{B}$ \\
& $2773(35)$ & $2825(35)$ & $2665(25)$ & $2794(31)$ & $2815(40)$ & $2810(30)-\mathrm{B}$ \\
4 & $2830(40)$ & $2760(35)$ & & $2848(30)$ & & $2775(30)-\mathrm{B}$ \\
& $1457(33)$ & $1550(35)$ & $1465(25)$ & $1581(29)$ & $1560(35)$ & $1460(25)-\mathrm{A}$ \\
5 & $1521(40)$ & $1510(35)$ & & $1570(27)$ & & $1545(25)-\mathrm{B}$ \\
& $1529(35)$ & $1475(35)$ & & & & \\
& $1526(39)$ & $1465(40)$ & $1550(25)$ & $1496(29)$ & $1505(35)$ & $1480(30)-\mathrm{A}$ \\
6 & & $1455(35)$ & & $1518(27)$ & & $1430(25)-\mathrm{B}$ \\
& $2796(36)$ & $2765(35)$ & $2740(25)$ & $2797(31)$ & $2745(35)$ & $2770(20)-\mathrm{A}$ \\
& $2778(42)$ & $2710(35)$ & & $2776(29)$ & & $2735(35)-\mathrm{B}$ \\
& & $2700(35)$ & & & & $2795(35)-\mathrm{B}$ \\
\hline
\end{tabular}

${ }^{\mathrm{a}} \mathrm{A}$ - Groningen method; B - leaching method.

The results show that the mean ages are close to those expected on the basis of the archaeological context or the previous dates, and that for individual samples, the range of results varies from approximately 100 to $200 \mathrm{yr}$. Using the procedure employed in Scott (2003), consensus values (the median values) are 2782, 1515, 2802, 1521, 1511, and 2767 BP. These values are only slightly different from the sample mean values. The mean quoted error is $32 \mathrm{yr}$, and the standard deviations for 
Table 4 Summary statistics.

\begin{tabular}{llll}
\hline Sample & $\begin{array}{l}\text { Mean } \\
(\mathrm{BP})\end{array}$ & $\begin{array}{l}\text { Standard deviation } \\
(\mathrm{yr})\end{array}$ & $\begin{array}{l}\text { Range } \\
(\mathrm{yr})\end{array}$ \\
\hline 1 & 2789 & 43 & 138 \\
2 & 1496 & 54 & 146 \\
3 & 2790 & 52 & 183 \\
4 & 1518 & 47 & 124 \\
5 & 1500 & 36 & 120 \\
6 & 2759 & 33 & 97 \\
\hline
\end{tabular}
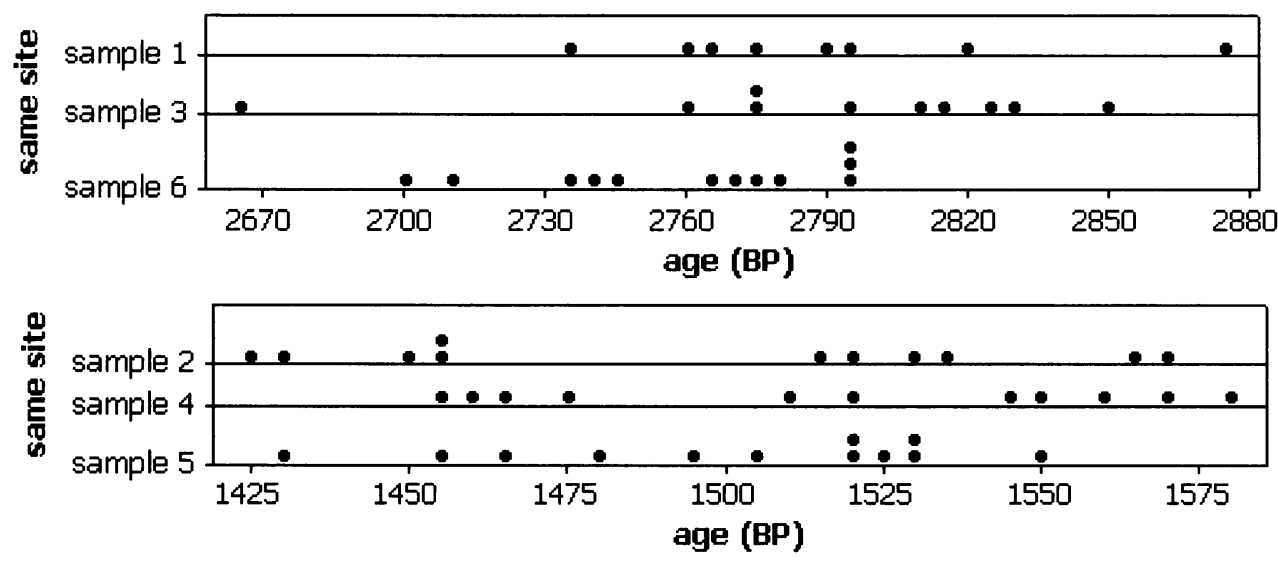

Figure 1 Sample results from Wapse (top) and Broechem (bottom).

the results for the 6 samples are 43,54,52,47,36, and $33 \mathrm{yr}$, respectively. When considered with the range, a few of the samples show evidence of greater scatter than would be expected given the quoted errors.

Table 5 shows the summary statistics for the $\delta^{13} \mathrm{C}$ values. For individual samples, there is considerable scatter, with ranges from $4-10 \%$ across the laboratories. The mean and median values for each sample range from -23.45 to $-26.00 \%$ and -23.30 to $-26.20 \%$, respectively. Some of the laboratories used $\delta^{13} \mathrm{C}$ values measured on their AMS systems, and these are sometimes not directly comparable with $\delta^{13} \mathrm{C}$ values measured using conventional mass spectrometers. This could account for some of the observed scatter in the $\delta^{13} \mathrm{C}$ values. Uneven cremation temperature might also be a factor.

Table $5 \delta^{13} \mathrm{C}$ values.

\begin{tabular}{lllll}
\hline & Mean & Median & Minimum & Maximum \\
\hline Sample 1 & -24.75 & -24.65 & -27.1 & -23.2 \\
Sample 2 & -25.47 & -25.80 & -29.7 & -19.1 \\
Sample 3 & -23.45 & -23.30 & -26.8 & -20.5 \\
Sample 4 & -26.00 & -26.20 & -31.3 & -23.2 \\
Sample 5 & -24.47 & -24.05 & -30.9 & -22.5 \\
Sample 6 & -24.35 & -24.00 & -28.2 & -21.4 \\
\hline
\end{tabular}




\section{The Statistical Analysis}

The statistical analysis has focused on assessing the agreement between duplicates as a measure of the repeatability of the measurement in relation to the quoted errors, and on an overall assessment of the laboratory comparability (reproducibility).

\section{Agreement Between Duplicates}

Duplicate samples provide an independent estimate of the repeatability of the measurement, assessed simply through their agreement. For the 20 analyses on samples 1 and 6 , the mean age is $2771 \mathrm{BP}$ and the standard deviation is $39 \mathrm{yr}$. The quoted errors vary between 25 and $42 \mathrm{yr}$, so the standard deviation is within this spread.

For the 23 analyses on samples 2 and 5, the mean age is $1498 \mathrm{BP}$ and the standard deviation is $45 \mathrm{yr}$. The quoted errors vary between 24 and $40 \mathrm{yr}$, so there is a slightly greater scatter in samples 2 and 5 than would be expected.

The analysis then focused on the differences between the duplicate pairs for the 2 sets. The maximum difference between duplicate pairs is $65 \mathrm{yr}$, the mean difference for all duplicate pairs is $-9 \mathrm{yr}$, and the standard deviation of the differences is $39 \mathrm{yr}$. The results show relatively good agreement between the duplicate samples. The spread in results amongst the laboratories for duplicate pairs is $39 \mathrm{yr}$, where the typical quoted error on an individual result was $24-42 \mathrm{yr}$.

\section{The Overall Agreement Amongst Laboratories}

From Figure 1b, 1 outlier was apparent and was removed from the results for sample 3. Taking account of the quoted error, standardized results, i.e. $\left({ }^{14} \mathrm{C}\right.$ age-mean)/quoted error, should show a Gaussian distribution with a mean of 0 and sigma of 1 , and approximately $95 \%$ of observations should then lie between +2 and -2 . Figure 2 shows the standardized results with $87 \%$ of all observations lying within these limits. Thus, there is evidence of slightly increased scatter beyond what would be expected.

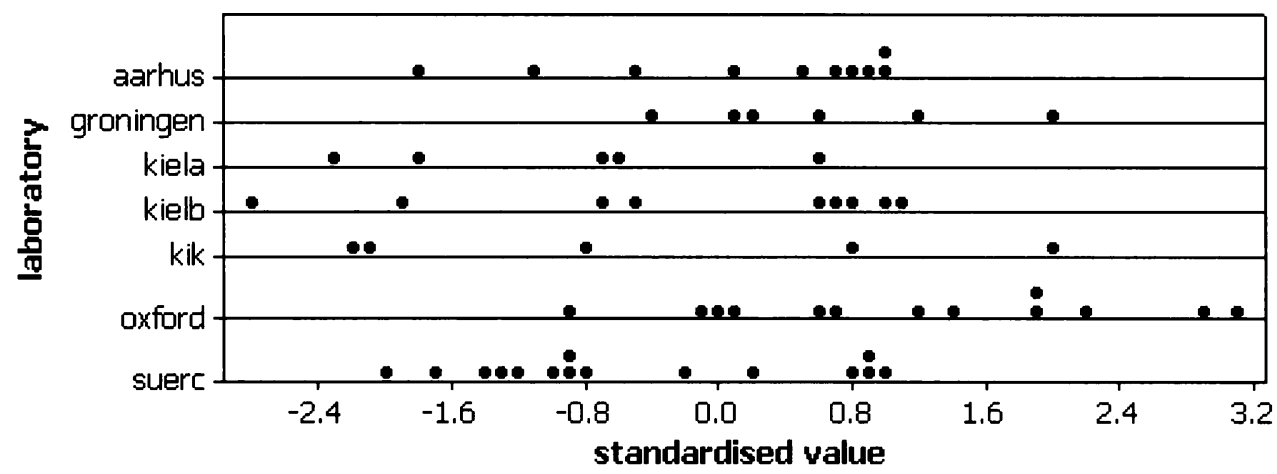

Figure 2 Standardized values versus laboratory

\section{CONCLUSIONS}

Using previously dated (or dated by association) cremated bone samples, 6 laboratories received 6 samples, producing a total of 64 analyses. These results have shown that the laboratories' measurements were in good agreement with the expected ${ }^{14} \mathrm{C}$ ages. The duplicate measurements were also 
in good agreement and showed a scatter only slightly greater than would be expected, given the quoted errors. The $\delta^{13} \mathrm{C}$ values show some scatter amongst laboratories, which may reflect small differences due to pretreatment methods. This variability warrants further investigation.

Cremated bone requires additional care in the selection of samples and in their pretreatment, but the results of the study show that when such care is exercised, dating cremated bone is both repeatable and reproducible.

In this study, the age was known only either from previous dates or through association, and the results showed good agreement with these expected ages. Further work would include dating cremated bone samples of independently known age and dating cremated and uncremated bone, ideally from the same skeletons or the same archaeological contexts, to demonstrate the absolute accuracy of the method.

\section{REFERENCES}

De Mulder G, Van Strydonck M, Boudin M. 2004. ${ }^{14} \mathrm{C}$ dateringen op gecremeerde menselijk bot uit de urnenvelden te Velzeke (O.-Vl.). Lunula 12:51-8. In Dutch.

Lanting JN, Brindley AL. 1998. Dating cremated bone: the dawn of a new era. Journal of Irish Archaeology 9: $1-7$.

Lanting JN, Aerts-Bijma, AT, van der Plicht J. 2001. Dating cremated bone. Radiocarbon 43(2A):249-54.

Mays S. 1998. The Archaeology of Human Bones. Lon- don: Routledge. 242 p.

Scott EM. 2003. The Third International Radiocarbon Intercomparison (TIRI) and The Fourth International Intercomparison (FIRI). Radiocarbon 45(2):135-408.

Van Stydonck M, Boudin M, Hoefkens M, De Mulder G. 2005. ${ }^{14} \mathrm{C}$ dating of cremated bones, why does it work? Lunula 13:3-10. Online at https://archive.ugent.be/retrieve/3095/14C-analyseLunulaXIII.pdf. 